\title{
Effect of pyrolysis temperature on gas permeation characteristics of poly(p-phenylene oxide) derived hollow fiber carbon membranes
}

\author{
Jaya M.A.T ${ }^{1,2}$, Harun W.M.H.W' ${ }^{1}$ Yusop M.F.M ${ }^{1}$, Ismail A.F and Ahmad M.A ${ }^{1,4 *}$ \\ ${ }^{1}$ School of Chemical Engineering, Engineering Campus, Universiti Sains Malaysia, 14300 Nibong Tebal, Penang, Malaysia \\ ${ }^{2}$ Membrane Science and Technology Cluster, Engineering Campus, Universiti Sains Malaysia, 14300 Nibong Tebal, Penang, Malaysia \\ ${ }^{3}$ Advanced Membrane Technology Research Centre, Universiti Teknologi Malaysia, 81310 Skudai, Johor, Malaysia \\ ${ }^{4}$ Solid Waste Management Cluster, Science E Engineering Research Centre, Engineering Campus, Universiti Sains Malaysia, Nibong \\ Tebal, Penang, Malaysia
}

\section{Article Info}

*Corresponding author:
Mohd Azmier Ahmad
Associate Professor
School of Chemical Engineering
Engineering Campus
Universiti Sains Malaysia
14300 NibongTebal, Penang, Malaysia
E-mail: chazmier@usm.my

Received: February 24, 2017

Accepted: March 31, 2017

Published: April 7, 2017

Citation: Jaya MAT, Harun WMHW, Yusop MFM, Ismail AF, Ahmad MA. Effect of pyrolysis temperature on gas permeation characteristics of poly ( $p$-phenylene oxide) derived hollow fiber carbon membranes. Int J Petrochem Res. 2017; 1(1): 12-14.

doi: 10.18689/ijpr-1000103

Copyright: (c) 2017 The Author(s). This work is licensed under a Creative Commons Attribution 4.0 International License, which permits unrestricted use, distribution, and reproduction in any medium, provided the original work is properly cited.

Published by Madridge Publishers

\begin{abstract}
Hollow fiber carbon membranes derived from poly( $p$-phenylene oxide) were subjected to different pyrolysis temperatures and their corresponding gas permeation characteristics were studied. Carbon membrane produced using pyrolysis temperature of $500^{\circ} \mathrm{C}$ was low in $\mathrm{H}_{2^{\prime}} \mathrm{O}_{2^{\prime}} \mathrm{N}_{2}$ and $\mathrm{CH}_{4}$ permeabilities, as well as $\mathrm{H}_{2} / \mathrm{N}_{2}$ and $\mathrm{O}_{2} / \mathrm{N}_{2}$ ideal selectivities. The highest permeabilities and ideal selectivities were obtained at $600^{\circ} \mathrm{C}$. Different trend was shown by the $\mathrm{CO}_{2}$ permeability which increased with pyrolysis temperature before decreased at $700^{\circ} \mathrm{C}$. The $\mathrm{CO}_{2} / \mathrm{CH}_{4}$ ideal selectivity consistently increased with increasing pyrolysis temperatures.
\end{abstract}

Keywords: Poly(p-phenylene oxide), Hollow fiber, Carbon membrane, Pyrolysis temperature, Gas separation.

\section{Introduction}

Carbon membranes possess the capability of discriminating gas molecules with similar kinetic diameters such as $\mathrm{O}_{2}$ and $\mathrm{N}_{2}[1]$. This feature has attracted many researchers to investigate and further develop the carbon membranes into commercially acceptance. Currently, the carbon membrane development focuses on finding new precursors and modification of the existing precursors. The precursors were mostly polyimides which is economically unattractive, thus non-polyimide polymers such as phenolic resin [2], cellulose acetate [3] and poly(furfuryl alcohol) [4] were extensively introduced. The current study reports interesting findings on the ideal gas separation characteristics of hollow fiber carbon membrane produced from poly(p-phenylene oxide) (PPO) using different pyrolysis temperature.

\section{Methods}

The hollow fiber PPO and carbon membranes were synthesized according to the previous work [5]. Heat treatments which were thermostabilization and pyrolysis, were applied to convert the PPO membrane into carbon membrane. The thermostabilization temperature was $240^{\circ} \mathrm{C}$ and held for 1 hour before proceeding to pyrolysis treatment at varied temperatures. A constant pressure/variable-volume system and a soap-bubble flow meter were used to measure the membrane flow rate. The membrane module was 
open/close-ended in which gas was fed from the membrane bore side. The order of the feed was $\mathrm{H}_{2^{\prime}} \mathrm{N}_{2^{\prime}} \mathrm{CO}_{2^{\prime}} \mathrm{CH}_{4}$ and $\mathrm{CO}_{2}$ to prevent strong adsorbing gases from influencing the measurement of the proceeding gases [6]. The morphology of the carbon membrane was captured using scanning electron microscope (SEM, Model Quanta FEG 450, FEI, USA).

\section{Results and discussions}

Fig. $1(a-b)$ and ( $c-d)$ shows the cross-sectional morphology of PPO and carbon membranes, respectively. Both membranes exhibited homogeneous, symmetric, and nonporous structure. The PPO and carbon membranes were approximately 15.4 and $14.7 \mu \mathrm{m}$ thick. The non-porous structure of the PPO membrane (PPOM) stemmed from the delayed phase inversion between the polymer solution and ethanol bore fluid and bath. The diameter and thickness of the membrane decreased after pyrolysis because of thermal shrinkage and decomposition. The change in surface morphology also suggested structure rearrangement during pyrolysis.
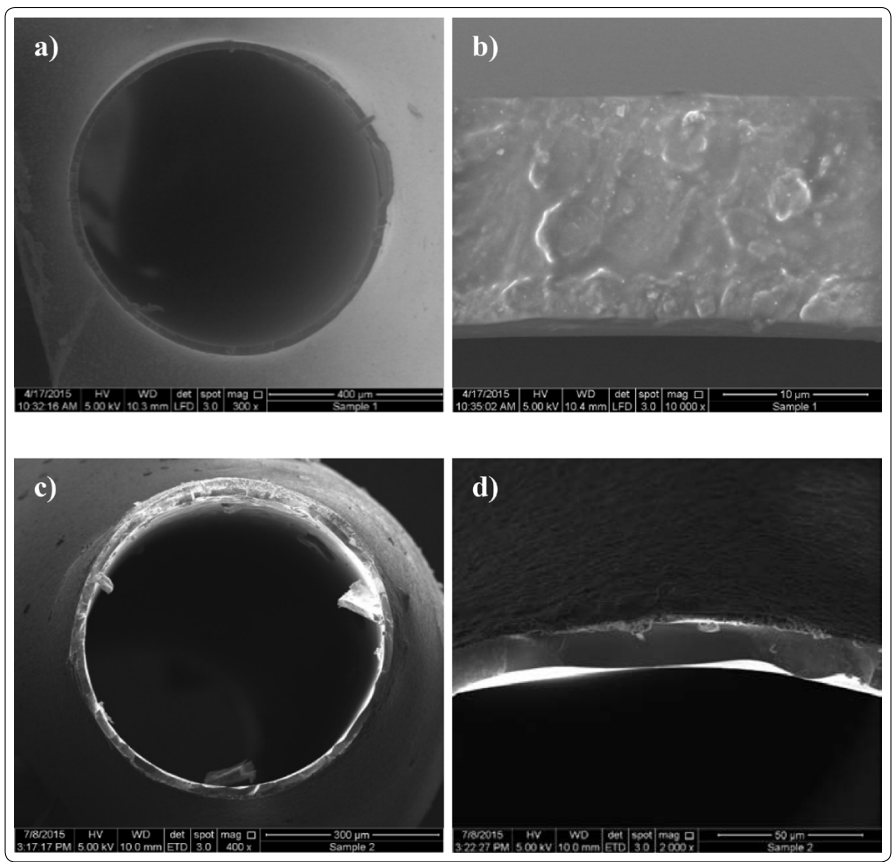

Figure 1. SEM images of cross-sectional views of PPO membrane $(a, b)$ and carbon membrane $(c, d)$

Figure 2 shows the permeabilities of $\mathrm{H}_{2^{\prime}} \mathrm{CO}_{2^{\prime}} \mathrm{O}_{2^{\prime}} \mathrm{CH}_{4}$ and $\mathrm{N}_{2}$ for carbon membranes pyrolyzed at $500^{\circ} \mathrm{C}(\mathrm{CM} 500), 600^{\circ} \mathrm{C}$ (CM600) and $700^{\circ} \mathrm{C}(\mathrm{CM} 700)$ with heating rate and thermal soak time of $1^{\circ} \mathrm{C} / \mathrm{min}$ and 15 mins, respectively. PPOM permeabilities was included for comparison purpose. The permeabilities of $\mathrm{H}_{2}, \mathrm{O}_{2}, \mathrm{~N}_{2}$ and $\mathrm{CH}_{4}$ dropped significantly when the sample was pyrolyzed to $500^{\circ} \mathrm{C}$. Similar trend was followed by their corresponding ideal selectivities of $\mathrm{O}_{2} / \mathrm{N}_{2}$ and $\mathrm{H}_{2} / \mathrm{N}_{2}$. In contrast, the $\mathrm{CO}_{2}$ permeability and $\mathrm{CO}_{2} / \mathrm{CH}_{4}$ ideal selectivity increased. As the pyrolysis temperature was increased to $600^{\circ} \mathrm{C}$, all the gas permeabilities and ideal selectivities increased significantly. The ideal separation performances of the gases, except $\mathrm{CO}_{2} / \mathrm{CH}_{4}$ ideal selectivity, decreased again as the pyrolysis temperature was further increased to $700^{\circ} \mathrm{C}$.
According to the values of permeabilities and ideal selectivities, particularly $\mathrm{O}_{2} / \mathrm{N}_{2^{\prime}}$ of the hollow fiber carbon membrane, the transport mechanism of the gases was most probably dominated by the molecular sieving in which it suggested that the membranes possessed micropore structure with pore size less than $2 \mathrm{~nm}$ [7] [8]. When the thermostabilized PPO membrane was subjected to pyrolysis treatment, slow decomposition of the polymer structure took place. At the same time, thermal shrinkage and structural rearrangement also occurred. The amorphous structure originated from the thermostabilized PPO membrane gradually collapsed during the pyrolysis and chaotically rearranged as amorphous carbon.

At $500^{\circ} \mathrm{C}$ the decomposition was not sufficient to develop highly porous membrane structure and the newly-developed pores were constantly decreased in size due to the thermal shrinkage. The decomposition to thermal shrinkage ratio might have increased significantly at pyrolysis temperature of $600^{\circ} \mathrm{C}$ as suggested by the substantial increases of the gas permeabilities. The decomposition rate reduced as the decomposable structure of the membrane not much left, resulting the dominance of structural densification when the pyrolysis temperature was further increased to $700^{\circ} \mathrm{C}$. The pores of carbon membrane might have collapsed and given away for the initiation of carbon graphitization which had higher density, tighter packaging and higher ordered structure [9].

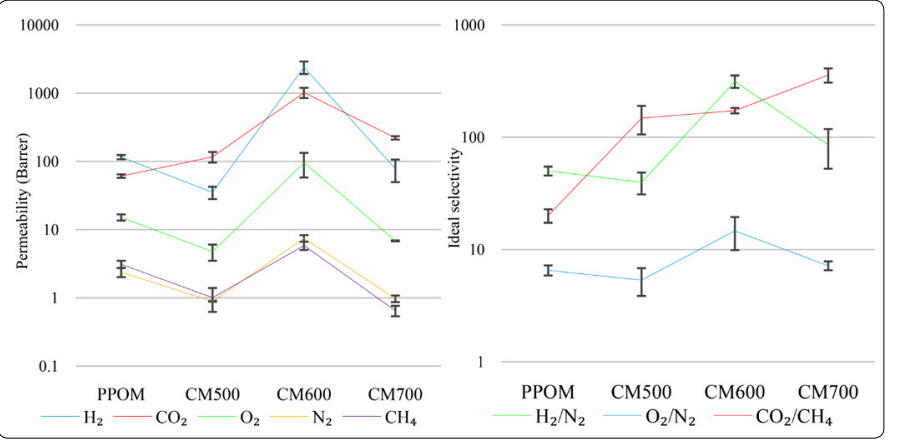

Figure 2. Permeabilities and ideal selectivities of PPO (PPOM) and PPO-derived hollow fiber carbon membrane (CM500, CM600 and CM700) prepared at different pyrolysis temperatures

The slightly higher $\mathrm{CO}_{2}$ permeabilities than their $\mathrm{H}_{2}$ counterparts as shown by the CM500 and CM700 indicated the presence of surface diffusion as one of the contributing transport mechanism besides molecular sieving effect. The lower $\mathrm{H}_{2}$ permeability on both membranes indicated that the resistance into the membrane was high most probably due to smaller openings than that of CM600. At the same time, this pore resistance also accelerated the accumulation of the highly adsorbable $\mathrm{CO}_{2}$ at the narrow opening which eventually provided suitable environment to produce surface diffusion effect that increased the $\mathrm{CO}_{2}$ permeability.

The affinity between the $\mathrm{CO}_{2}$ and carbon membrane pore wall suggested that kinetic diameter was not the sole factor in determining the magnitude of the gas permeabilities, but also the affinity of the diffusing molecules towards the carbon membrane pore wall [10]. This affinity is originated from the 
van der Waal's forces produced by quadrupole moment of the symmetrical $\mathrm{CO}_{2}$ that established weak attraction towards the carbon pore walls which occupied with delocalized electrons from its turbostratic structure.

\section{Conclusion}

The morphology of the PPO-derived hollow fiber carbon membrane was dense, homogenous, thin and symmetric. Each stage of pyrolysis temperature has significant impact on the PPO-derived carbon membrane structures. The highest permeabilities and ideal selectivities were obtained at $600^{\circ} \mathrm{C}$. In exception of $\mathrm{CO}_{2}$ permeability and $\mathrm{CO}_{2} / \mathrm{CH}_{4}$ ideal selectivity, all permeabilities and ideal selectivities were very low when pyrolysis temperature of $500^{\circ} \mathrm{C}$ was used. The transport mechanism through the carbon membranes was highly affected by molecular sieving and surface diffusion. The surface diffusion transport mechanism was highly dominating when the carbon membranes possessed very small pore sizes.

\section{Acknowledgements}

The authors are grateful for the funding from Solid Waste Management Cluster (1001/CKT/870023), Membrane Science and Technology Cluster (1001/PSF/8610011), Postgraduate Research grant of Universiti Sains Malaysia and Mybrain 15 fellowship of Ministry of Higher Education, Malaysia.

\section{References}

1. Barsema JN, Balster J, Jordan V, Van der Vegt NF, Wessling M. Functionalized carbon molecular sieve membranes containing Agnanoclusters. J Membrane Sci. 2003; 219(1-2): 47-57. doi: 10.1016/ S0376-7388(03)00176-5

2. Tanco M, Tanaka D, Rodrigues S, Texeira M, Mendes A. Compositealumina-carbon molecular sieve membranes prepared from novolac resin and boehmite. Part I: Preparation, characterization and gas permeation studies. Int J Hydrogen Energy. 2015; 40(16): 5653-5663. doi: 10.1016/j.jijhydene.2015.02.112

3. He X, Hagg M. Structural, kinetic and performance characterization of hollow fiber carbon membranes. J Membrane Sci. 2012; 390-391: 23-31. doi: 10.1016/j.memsci.2011.10.052

4. Zhong Z, Yao J, Low Z, Chen R, He M, Wang H. Carbon composite membrane derived from a two-dimensional zeolitic imidazolate framework and its gas separation properties. Carbon. 2014; 72: 242-249. doi: 10.1016/j.carbon.2014.01.072

5. Yoshimune M, Fujiwara I, Suda $H$, Haraya K. Novel carbon molecular sieve membranes derived from poly(phenylene oxide) and its derivatives for gas separation. Chem Lett. 2005; 34: 958-959. doi: 10.1246/ cl.2005.958

6. He X, Lie J, Sheridan E, Hagg M. Preparation and characterization of hollow fiber carbon membranes from cellulose acetate precursors. Ind. Eng. Chem. Res. 2011; 50(4): 2080-2087. doi: 10.1021/ie101978q

7. Shelekhin $A B$, Dixon AG, MaYH. Theory of gas diffusion and permeation in inorganic molecular-sieve membranes. AlChe J. 1995; 41(1): 58-67. doi: 10.1002/aic.690410107

8. Salleh WNW, Ismail AF. Fabrication and characterization of PEI/PVPbased carbon hollow fiber membranes for $\mathrm{CO}_{2} / \mathrm{CH}_{4}$ and $\mathrm{CO}_{2} / \mathrm{N}_{2}$ separation. AlChe J. 2011; 58(10): 3167-3175. doi: 10.1002/aic.13711

9. Chen X, Khoo KG, Kim MW, Hong L. Deriving a CO2-permselective carbon membrane from a multi-layered matrix of polyion complexes. ACS Appl Mater Inter. 2014; 6(13): 10220-10230. doi: 10.1021/am5015953

10. Meng L. Park S. Investigation of narrow pore size distribution on carbon dioxide capture of nanoporous carbons. Bull Korean Chem Soc. 2012; 33(11): 3749-3754. 